\title{
Use of an excision reporter plasmid to study the intracellular mobility of the conjugative transposon Tn916 in Gram-positive bacteria
}

\author{
Jean Celli, Claire Poyart and Patrick Trieu-Cuot
}

Author for correspondence: Patrick Trieu-Cuot. Tel: +33140615679 . Fax: +33140615592.

\begin{abstract}
Laboratoire de
Microbiologie, Faculté de Médecine Necker-Enfants Malades, 75730 Paris

Cedex 15, France
\end{abstract}

\begin{abstract}
An excision reporter plasmid was constructed to characterize the intracellular mobility of Tn916 in various Gram-positive bacteria. The reporter component of this plasmid is a chloramphenicol-resistance gene which has been insertionally inactivated with the integrative vector PAT112 containing the attachment site of Tn916. Tn916-mediated excision of pAT112, to produce clones resistant to chloramphenicol, was detected in Enterococcus faecalis BM4110, Listeria monocytogenes L028-Str and Streptococcus gordonii BM120, but not in Lactococcus lactis MG1363-RF or in Streptococcus pneumoniae BM124, and always depended upon the ability of the bacterial host to generate circular forms of the transposon. The results suggest that (i) the excision event, although required, is not sufficient for conjugal transfer to occur and (ii) there is no linear relationship between the donor potential of $E$. faecalis strains and either the excision frequency of pAT112 or the copy number of Tn916 circular intermediates per cell in these hosts. Excision of pAT112 occurred mainly during the late exponential phase of growth of $E$. faecalis and $L$. monocytogenes and this recombination event was not stimulated by heat shock, salt and alcohol stresses or by the presence of tetracycline in the medium.
\end{abstract}

Keywords: conjugative transposons, $\operatorname{Tn} 916$, excision, conjugation

\section{INTRODUCTION}

The $18 \mathrm{~kb}$ transposon Tn916, first detected in the chromosome of Enterococcus faecalis strain DS16, is the prototype of a closely related family of conjugative transposons widespread in Gram-positive cocci (Clewell et al., 1995; Scott \& Churchward, 1995). Transposable elements which belong to this family are large DNA segments $(\geqslant 18 \mathrm{~kb})$ and contain the tetracycline-resistance determinant tet $(M)$ either alone (e.g. Tn916) or associated with other resistance genes (e.g. Tn3703 and Tn1545). Transposition of these elements proceeds by excision to a free, non-replicative, covalently closed circular intermediate that is a substrate for integration. The integration-excision system of these elements is structurally and functionally related to that of lambdoid phages (Poyart-Salmeron et al., 1989, 1990). Excision and integration occur by reciprocal site-specific recombination between non-homologous sequences of 6 bp. Excisive recombination requires two transposonencoded proteins, an excisionase (Xis- Tn) and an integrase (Int-Tn), whereas integration requires only Int-Tn. However, as in the $\lambda$ site-specific recombination system, Int-Tn alone can catalyse a low level of excision but this activity is greatly stimulated by Xis-Tn. It is thus likely that the direction of recombination, integration versus excision, is determined by the relative amounts of the two proteins in a cell.

Conjugal transfer of Tn916 and related elements can be viewed as a transposition event involving donor and recipient replicons that happen to be present in different cells and is therefore referred to as conjugative transposition. This event involves circularization of the element in the donor, and transfer of the non-replicative intermediate by conjugation to the recipient where it integrates (Storrs et al., 1991). Bacterial hosts such as Lactococcus lactis in which Tn916 cannot excise are unable to promote conjugative transposition (Bringel et al., 1991). Thus, in addition to their transfer functions, transfer of this class of elements requires transposonencoded excision and integration functions. The complete nucleotide sequence of $\operatorname{Tn} 916$ has been determined (Flannagan et al., 1994), which enabled the identification of some putative polypeptides displaying significant homology with other known proteins involved in 
conjugation (antirestriction protein Ard of plasmid Collb-P9, MbeA mobilization protein of plasmid ColE1) and the location of a functional oriT (Jaworski \& Clewell, 1995).

The frequency of conjugative transposition of Tn916 between isogenic strains of $E$. faecalis may range over more than four orders of magnitude between different Tn916-containing donors and is not related to the number of transposon insertions in the donor strain, although strains with a high donor potential generally contain multiple insertions. The host range of transfer of Tn916 might depend on the donor potential of the transposon-delivery strain: only strains having a high donor potential can undergo conjugative transposition from Gram-positive to Gram-negative bacteria (Poyart et al., 1995). Tn916 insertions located at different sites of the bacterial genome may possess different donor potentials when considered independently and it has been suggested that the insertion with the greatest potential would be the most likely to excise initially and that this event could stimulate, by trans-activation, movements of all other transposons present in the cell (Flannagan \& Clewell, 1991). The dosage of Tn916 circular intermediates in E. faecalis performed by quantitative PCR assay has revealed that the frequency of $\operatorname{Tn} 916$ conjugation is dependent on the copy number of circular intermediates present in the donor cell population (Manganelli et al., 1995). Thus, excision appears to be the initial and rate-limiting step of both the intracellular and intercellular mobility of this class of elements. In this study, we have constructed an excision reporter plasmid to characterize, qualitatively and quantitatively, the intracellular mobility of Tn916 in various Gram-positive bacteria including isogenic strains with different donor potential. Our results are not fully consistent with the mechanism of transactivation described above and do not support the proposal that there is a linear relationship between excision and transfer.

\section{METHODS}

Bacterial strains and growth conditions. The main characteristics of the bacterial strains and plasmids used in this study are listed in Table 1 . All the strains were grown at $37^{\circ} \mathrm{C}$ in brain heart infusion (BHI) broth or on BHI agar plates (Difco). Streptococcus gordonii and Streptococcus pneumoniae were grown on BHI blood agar and incubated under a $5 \% \mathrm{CO}_{2}$ moist atmosphere. For Gram-positive bacteria, antibiotics were used at the following concentrations: streptomycin, $1000 \mu \mathrm{g} \mathrm{ml}^{-1}$; rifampicin, $40 \mu \mathrm{g} \mathrm{ml}^{-1}$; fusidic acid, $20 \mu \mathrm{g} \mathrm{ml}^{-1}$; chloramphenicol, $20 \mu \mathrm{g} \mathrm{ml}^{-1}\left(\right.$ E. faecalis), $10 \mu \mathrm{g} \mathrm{m}^{-1}$ (L. lactis, Listeria monocytogenes) or $5 \mu \mathrm{g} \mathrm{m}^{-1}$ (S. gordonii, $S$. pneumoniae); erythromycin, $8 \mu \mathrm{g} \mathrm{ml}^{-1}$; tetracycline, $8 \mu \mathrm{g} \mathrm{ml}^{-1}$. For Escherichia coli, $20 \mu \mathrm{g}$ chloramphenicol $\mathrm{ml}^{-1}$, $60 \mu \mathrm{g}$ spectinomycin $\mathrm{ml}^{-1}$ and $8 \mu \mathrm{g}$ tetracycline $\mathrm{ml}^{-1}$ were used.

DNA manipulations. Plasmid DNA was extracted from E. coli as described by Sambrook et al. (1989). Total DNA from Gram-positive bacteria was purified as described previously by Storrs et al. (1991). Restriction endonucleases and T4 DNA ligase were purchased from New England Biolabs and were used according to the manufacturer's recommendations.
Restriction-endonuclease-generated DNA fragments were separated by electrophoresis on $0 \cdot 8 \%(\mathrm{w} / \mathrm{v})$ agarose gels and transferred to reinforced nitrocellulose BA-S 83 membranes (Schleicher \& Schuell). Prehybridization and hybridization were performed under stringent conditions as described by Sambrook et al. (1989). DNA probes were labelled with [ $\alpha$ ${ }^{32}$ P]dCTP (Amersham) by using the Nick Translation kit (Amersham). Detection of the segments corresponding to the transposon attachment site (att-Tn) specific for Tn916 circular intermediates and to the transposon integrase gene int-Tn was carried out by PCR using the oligonucleotides CT31 plus CT32 (Storrs et al., 1991) and $\mathrm{O}_{\text {int1 }}\left(5^{\prime}\right.$-GTCGTATCAAGGCTCTTTCC- $\left.3^{\prime}\right)$ plus $\mathrm{O}_{\text {int2 }}$ (5'-GTACTACTAAGCAACAAGACGC- $3^{\prime}$ ), respectively. PCR reactions were performed in a final volume of $100 \mu \mathrm{l}$ containing $50 \mathrm{ng}$ genomic DNA, $0 \cdot 1 \mu \mathrm{M}$ each primer, $200 \mu \mathrm{M}$ each deoxynucleoside triphosphate and 2 U Taq DNA polymerase in $1 \times$ amplification buffer $(10 \mathrm{mM}$ Tris/ $\mathrm{HCl}, \mathrm{pH} 8.3 ; 50 \mathrm{mM} \mathrm{KCl} ; 1.5 \mathrm{mM} \mathrm{MgCl}_{2}$ ). The PCR mixture was submitted to a denaturation step (10 min at $95^{\circ} \mathrm{C}$ ), followed by 35 cycles of amplification $(60 \mathrm{~s}$ of annealing at $55^{\circ} \mathrm{C}, 90 \mathrm{~s}$ of elongation at $72^{\circ} \mathrm{C}$ and $60 \mathrm{~s}$ of denaturation at $95^{\circ} \mathrm{C}$ ).

Mating experiments. Overnight cultures of donor and recipient cells were diluted $1: 100$ in fresh BHI broth without antibiotics. Cells were grown for $5 \mathrm{~h}$ (approximate $\mathrm{OD}_{600} 0 \cdot 7$ ) and $100 \mu \mathrm{l}$ each of donors and recipients was mixed and spread onto $0.45 \mu \mathrm{m}$ pore-size nitrocellulose membrane filters (Millipore) placed on BHI agar plates. After $18 \mathrm{~h}$ incubation at $37^{\circ} \mathrm{C}$, cells were suspended in $1 \mathrm{ml} 0.9 \% \mathrm{NaCl}$ and serial dilutions of this mixture were plated on BHI agar containing appropriate antibiotics to select transconjugants and to enumerate donor cells. Transfer frequencies were expressed as the number of transconjugants per donor c.f.u. after the mating period.

Construction of the excision reporter plasmid pTCR9. The $901 \mathrm{bp}$ TaqI-Sau3A DNA fragment containing the cat gene of the streptococcal plasmid pIP501 (Trieu-Cuot et al., 1992) was cloned into pGB2 to produce pTCR7. Plasmid pAT112 is a mobilizable and integrative vector that utilizes the transposition properties of $\operatorname{Tn} 1545 / \operatorname{Tn} 916$. Competent cells of $E$. coli SM10 harbouring pAT112 and pTCR7 were transformed (Sambrook et al., 1989) with $1 \mu \mathrm{g}$ pAT294 DNA, a pUC18derivative directing synthesis of the transposon-encoded integrase Int-Tn. After heat shock, the cells were diluted 10fold in BHI broth containing ampicillin and incubated for $5 \mathrm{~h}$ with gentle agitation. Serial dilutions of the culture were mixed with an equal volume of a late exponential phase culture of $E$. coli K802N:: Tn10 and the resulting mixture was plated on $\mathrm{BHI}$ agar containing spectinomycin and tetracycline to select E. coli K802N : : Tn10 transconjugants harbouring cointegrates of the integrative vector and of the target replicon. Analysis of the plasmid content of chloramphenicol-susceptible $\left(\mathrm{Cm}^{\mathrm{s}}\right)$ transconjugants by agarose gel electrophoresis showed two classes of pTCR7::pAT112 co-integrates on the basis of their Sau3A restriction profiles. The insertion site of pAT112 was characterized on one plasmid representative of each class by double-stranded DNA template sequencing (Zhang et al., 1988), using a Sequenase 2.0 kit (United States Biochemical) and the oligonucleotides CT31 and CT32. Insertion of pAT112 had occurred either in the cat promoter region or at position 333 of the 643-bp-long cat gene (TrieuCuot et al., 1992). The plasmid of the latter class, designated pTCR8, was introduced by transformation (Trieu-Cuot et al., 1988) into $S$. gordonii harbouring the low copy number plasmid pIL205, a pIP501 derivative conferring resistance to chloramphenicol but not to erythromycin, and transformants 
Table 1. Bacterial strains and plasmids used in this study

\begin{tabular}{|c|c|c|}
\hline Strain*/plasmid & Relevant properties $\dagger$ & Reference or origin \\
\hline \multicolumn{3}{|l|}{ Strains } \\
\hline \multicolumn{3}{|c|}{ Enterococcus faecalis } \\
\hline BM4110 & Str (spontaneous mutant of $\mathrm{JH} 2$ ) & Courvalin \& Carlier (1986) \\
\hline $\mathrm{JH} 2-2$ & Rif, Fus (spontaneous mutant of JH2) & Jacobs \& Hobbs (1974) \\
\hline NEM429 & BM4110:: Tn916 (four copies), Str Tc & This study \\
\hline NEM575 & BM4110:: Tn916 (two copies), Str Tc & This study \\
\hline NEM574 & BM4110:: Tn916 (one copy), Str Tc & This study \\
\hline \multicolumn{3}{|c|}{ Listeria monocytogenes } \\
\hline L028-Str & Str (spontaneous mutant of L028) & This study \\
\hline NEM766 & L028-Str::Tn916 (one copy), Str Tc & This study \\
\hline \multicolumn{3}{|c|}{ Streptococcus gordonii } \\
\hline BM120 & Str & Le Bouguénec et al. (1984) \\
\hline NEM768 & BM120:: Tn916 (one copy), Str Tc & This study \\
\hline \multicolumn{3}{|c|}{ Streptococcus pneumoniae } \\
\hline BM124 & Str & Le Bouguénec et al. (1984) \\
\hline NEM751 & BM124:: Tn916 (two copies), Str Tc & This study \\
\hline BM4200 & Wild strain carrying $\mathrm{Tn} 1545, \mathrm{Cm} \mathrm{Km} \mathrm{Em} \mathrm{Tc}$ & Courvalin \& Carlier (1986) \\
\hline \multicolumn{3}{|c|}{ Lactococcus lactis } \\
\hline MG1363-RF & Rif Fus (spontaneous mutant of MG1363) & Poyart \& Trieu-Cuot (1994) \\
\hline NEM536 & MG1363-RF:: Tn916 (one copy), Rif Fus Tc & This study \\
\hline \multicolumn{3}{|l|}{ Escherichia coli } \\
\hline SM10 & $\begin{array}{l}\mathrm{F}^{-}, \mathrm{RP} 4-2-\mathrm{Tc}:: \mathrm{Mu}, \mathrm{Km}, \text { thi-1 recA1 thr-1 leuB6 tonA21 supE44 } \lambda^{-} \\
\text {lacY1, Tra }\end{array}$ & Simon et al. (1983) \\
\hline $\mathrm{K} 802 \mathrm{~N}:: \operatorname{Tn} 10$ & $h s d R$ hsdM $M^{+}$gal met supE, Nal Rif Tc & Trieu-Cuot et al. (1988) \\
\hline \multicolumn{3}{|l|}{ Plasmids } \\
\hline pGB2 & $\mathrm{Sp} / \mathrm{Sm}$, oriR pSC101, $4.0 \mathrm{~kb}$ & Churchward et al. (1984) \\
\hline pAT112 & Em, $\mathrm{Tra}^{-}, \mathrm{Mob}^{+}$, oriR pACYC184, att-Tn1545, $4.9 \mathrm{~kb}$ & Trieu-Cuot et al. (1991) \\
\hline pIL205 & $\mathrm{Cm}, \mathrm{Tra}^{+}, 27 \cdot 3 \mathrm{~kb}$ & Langella et al. (1993) \\
\hline pAT294 & $\begin{array}{l}\text { Ap, pUC18 with a } 1.8 \mathrm{~kb} \text { Sspl-Sau3A fragment carrying int-Tn, } \\
4.6 \mathrm{~kb}\end{array}$ & Poyart-Salmeron et al. (1989) \\
\hline pTCR7 & $\begin{array}{l}\text { pGB2 with a } 0.9 \mathrm{~kb} \text { TaqI-Sau3A fragment containing cat of pIP501, } \\
\mathrm{Sp} / \mathrm{Sm} \mathrm{Cm}, 4.9 \mathrm{~kb}\end{array}$ & $\begin{array}{l}\text { Trieu-Cuot et al. (1992) and } \\
\text { this study }\end{array}$ \\
\hline pTCR8 & pTCR7::pAT112, pAT112 integrated into cat, Sp/Sm Em, $9 \cdot 8 \mathrm{~kb}$ & This study \\
\hline pTCR9 & pIL205::pAT112, Em, $32 \cdot 2 \mathrm{~kb}, \mathrm{Tra}^{+}$ & This study \\
\hline
\end{tabular}

* Bacteria were grown in BHI broth or agar.

† Ap, Cm, Em, Fus, Km, Nal, Rif, Sm (or Str), Sp and Tc indicate resistance to ampicillin, chloramphenicol, erythromycin, fusidic acid, kanamycin, nalidixic acid, rifampin, streptomycin, spectinomycin and tetracycline, respectively.

were selected on BHI agar containing $5 \%$ defibrinated horse serum and erythromycin. Six selected transformants were tested for antibiotic resistance by agar disk diffusion, and their plasmid contents were analysed by agarose gel electrophoresis. As expected, all the clones were erythromycin-resistant $\left(\mathrm{Em}^{\mathrm{R}}\right)$ but were $\mathrm{Cm}^{\mathrm{s}}$ and contained a single plasmid of $32 \cdot 2 \mathrm{~kb}$, i.e. the size of pIL205 $(27 \cdot 3 \mathrm{~kb})$ plus that of pAT112 $(4.9 \mathrm{~kb})$. This plasmid, designated pTCR9 (Fig. 1), retained the relevant characteristics of the parental replicon pIP501: it transfers efficiently by filter mating, but not in liquid media, to a large variety of Gram-positive bacteria, where it replicates stably in the absence of selective pressure.

Excision assay. Tn916-mediated excision of pAT112 from pTCR9 was monitored as follows. Bacterial strains harbouring the excision reporter plasmid pTCR9 were grown overnight at $37^{\circ} \mathrm{C}$ in $\mathrm{BHI}$ broth containing erythromycin, diluted 1:100 in preheated BHI broth and incubated with gentle agitation in a rollerdrum to prevent sedimentation of cells. Aliquots of the cultures were removed at the desired period of growth, serially diluted and plated both on BHI agar containing chloramphenicol to enumerate clones in which pAT112 has excised from pTCR9, and hence designated excisants, and on $\mathrm{BHI}$ agar without antibiotics to enumerate the cells. In each experiment, we studied the ability of selected excisants to transfer by conjugation at a high frequency (i.e. that of pIL205) their chloramphenicol-resistant $\left(\mathrm{Cm}^{\mathrm{R}}\right)$ determinant to an appropriate $E$. faecalis recipient. The excision frequency of pAT112 from pTCR9 was expressed as the number of $\mathrm{Cm}^{\mathrm{R}}$ excisants/total c.f.u., after $48 \mathrm{~h}$ incubation at $37^{\circ} \mathrm{C}$. For salt, alcohol, antibiotic or heat stresses, cultures of E. faecalis NEM429 harbouring pTCR9 were grown at $37^{\circ} \mathrm{C}$ to late exponential phase $\left(10^{9}\right.$ c.f.u. $\left.\mathrm{ml}^{-1}\right)$. At this point, the cells were stressed for $30 \mathrm{~min}$ by addition (final concentration) of $\mathrm{NaCl}(2 \mathrm{M})$, ethanol $(10 \%, \mathrm{v} / \mathrm{v})$ or tetracycline $\left(10 \mu \mathrm{g} \mathrm{ml}^{-1}\right)$, or were transferred to $45^{\circ} \mathrm{C}$. Each experiment was carried out in duplicate and the excision frequency of 
pAT112 from pTCR9 was determined immediately after the stress treatment as described above.

\section{RESULTS}

\section{Donor potential of Tn916 delivery strains}

The conjugative transposon Tn916 was transferred by conjugation from a suitably marked $E$. faecalis donor to E. faecalis BM4110, L. monocytogenes L028-Str, S. gordonii BM120, S. pneumoniae BM124 and L. lactis MG1363-RF. In each experiment, the ability of 12 selected transconjugants to deliver Tn916 into the appropriate E. faecalis recipient, JH2-2 or BM4110, was evaluated by filter mating. Retransfer of $\operatorname{Tn} 916$ was obtained with E. faecalis or L. monocytogenes donors but was never observed when S. gordonii, S. pneumoniae and L. lactis were used as transposon delivery strains (Table 2 and data not shown). During the course of this work, we isolated three E. faecalis strains (NEM429, NEM574 and NEM575) that delivered Tn916 at significantly different frequencies (Table 2). One strain of $L$. monocytogenes (NEM766), S. gordonii (NEM768), S. pneumoniae (NEM751) and L. lactis (NEM536) harbouring Tn916 was also selected for further studies. Southern analysis was used to determine the number of copies of Tn916 in these strains (Table 1), evaluated as the number of transposon-chromosome junction fragments containing int-Tn (Fig. 3, lanes 1, 7 and 13, shows part of this analysis).

\section{Excision of pAT112 in bacterial hosts harbouring Tn916}

The structure of plasmid pTCR9 is shown in Fig. 1. The reporter component of this plasmid is a cat gene which has been insertionally inactivated with an integrative vector containing the att-Tn site of $\operatorname{Tn} 1545$ which is identical to that of Tn916. The functioning of this reporter plasmid system is based on the fact that the two transposon-encoded proteins that are required for excision of this class of transposon will freely diffuse in the cytoplasm of the cells (Poyart-Salmeron et al., 1989).

Table 2. Analysis of the excision and transfer events in different bacterial strains harbouring Tn916

\begin{tabular}{|c|c|c|c|c|c|c|c|}
\hline \multirow[t]{2}{*}{$\begin{array}{l}\text { Bacterial host harbouring } \\
\text { pTCR9* }\end{array}$} & \multirow[t]{2}{*}{ Trial } & \multirow{2}{*}{$\begin{array}{c}\text { Excision } \\
\text { frequency } \\
\text { of pAT112† }\end{array}$} & \multicolumn{4}{|c|}{$\begin{array}{l}\text { Relevant resistance phenotype of } \mathrm{Cm}^{\mathrm{R}} \\
\text { excisants }(\%)\end{array}$} & \multirow{2}{*}{$\begin{array}{c}\text { Transfer } \\
\text { frequency of } \\
\text { Tn916 to } \\
\text { JH2-2‡ }\end{array}$} \\
\hline & & & $\mathrm{Tc}^{\mathrm{s}} \mathrm{Em}^{\mathrm{s}}$ & $\mathrm{Tc}^{\mathrm{S}} \mathrm{Em}^{\mathrm{R}}$ & $\mathrm{Tc}^{\mathrm{R}} \mathrm{Em}^{\mathrm{S}}$ & $\mathrm{Tc}^{\mathrm{R}} \mathrm{Em}^{\mathrm{R}}$ & \\
\hline \multicolumn{8}{|l|}{ E. faecalis } \\
\hline BM4110 & 1 & $<10^{-9}$ & - & - & - & - & - \\
\hline \multirow[t]{2}{*}{ NEM429 (four copies of $\operatorname{Tn} 916$ ) } & 1 & $2.6 \times 10^{-7}$ & 0 & 5 & 90 & 5 & $6.7 \times 10^{-6}$ \\
\hline & 2 & $2.7 \times 10^{-7}$ & 10 & 0 & 80 & 10 & $5 \cdot 1 \times 10^{-6}$ \\
\hline \multirow[t]{2}{*}{ NEM575 (two copies of Tn916) } & 1 & $4.5 \times 10^{-8}$ & 60 & 0 & 20 & 20 & $2 \cdot 1 \times 10^{-7}$ \\
\hline & 2 & $5.0 \times 10^{-8}$ & 69 & 6 & 25 & 0 & $3.6 \times 10^{-7}$ \\
\hline \multirow[t]{2}{*}{ NEM574 (one copy of Tn916) } & 1 & $8.7 \times 10^{-8}$ & 89 & 11 & 0 & 0 & $1 \cdot 1 \times 10^{-8}$ \\
\hline & 2 & $8.0 \times 10^{-8}$ & 80 & 20 & 0 & 0 & $8 \cdot 8 \times 10^{-9}$ \\
\hline \multicolumn{8}{|l|}{ L. monocytogenes } \\
\hline L028-Str & 1 & $<10^{-9}$ & - & - & - & - & - \\
\hline \multirow[t]{2}{*}{ NEM766 (one copy of $\operatorname{Tn} 916$ ) } & 1 & $5.5 \times 10^{-6}$ & 100 & 0 & 0 & 0 & $5.5 \times 10^{-6}$ \\
\hline & 2 & $4.2 \times 10^{-6}$ & 90 & 10 & 0 & 0 & $6.3 \times 10^{-6}$ \\
\hline \multicolumn{8}{|l|}{ S. gordonii } \\
\hline BM120 & 1 & $<10^{-9}$ & - & - & - & - & - \\
\hline \multirow[t]{2}{*}{ NEM768 (one copy of $\operatorname{Tn} 916$ ) } & 1 & $2 \cdot 7 \times 10^{-6}$ & 60 & 40 & 0 & 0 & $<10^{-9}$ \\
\hline & 2 & $0 \cdot 9 \times 10^{-6}$ & 67 & 33 & 0 & 0 & $<10^{-9}$ \\
\hline \multicolumn{8}{|l|}{ S. pneumoniae } \\
\hline BM124 & 1 & $<10^{-8}$ & - & - & - & - & - \\
\hline \multirow[t]{2}{*}{ NEM751 (two copies of Tn916) } & 1 & $<10^{-8}$ & - & - & - & - & $<10^{-8}$ \\
\hline & 2 & $<10^{-8}$ & - & - & - & - & $<10^{-8}$ \\
\hline \multicolumn{8}{|l|}{ L. lactis } \\
\hline MG1363-RF & 1 & $<10^{-9}$ & - & - & - & - & - \\
\hline \multirow[t]{2}{*}{ NEM536 (one copy of $\operatorname{Tn} 916$ ) } & 1 & $<10^{-9}$ & - & - & - & - & $<10^{-9} \mathbb{S}$ \\
\hline & 2 & $<10^{-9}$ & - & - & - & - & $<10^{-9} \mathbb{S}$ \\
\hline
\end{tabular}

"NEM429, NEM575 and NEM574 are BM4110::Tn916; NEM766 is L028-Str::Tn916; NEM768 is BM120::Tn916; NEM751 is BM124:: Tn916; and NEM536 is MG1363-RF:: Tn916.

$\dagger$ Number of $\mathrm{Cm}^{\mathrm{R}}$ c.f.u./total c.f.u. in early stationary phase.

$\ddagger$ Number of transconjugants per donor c.f.u. after mating.

$\$ E$. faecalis BM4110 was used as a recipient in these matings. 


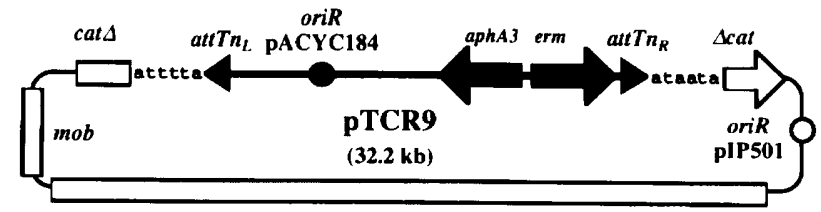

tra

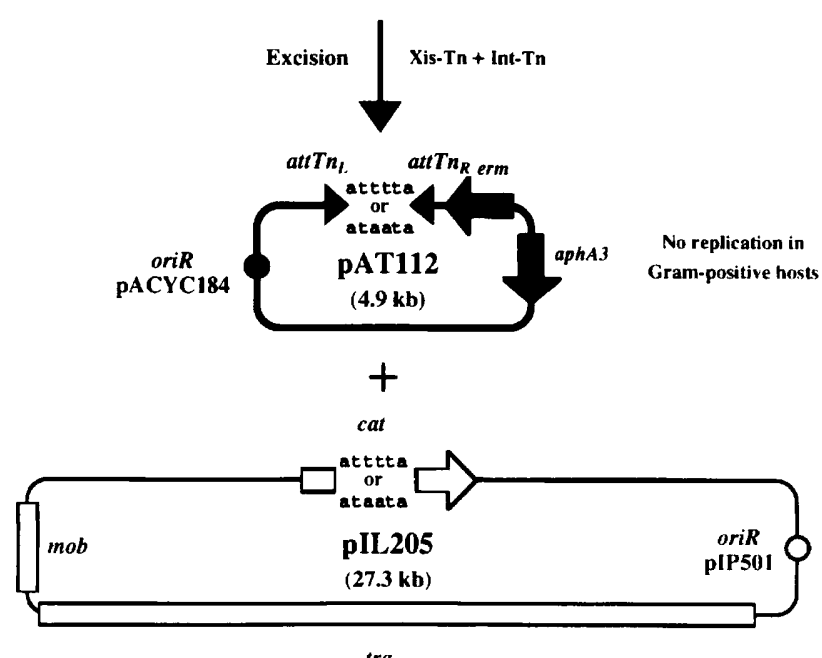

tra

Fig. 1. Structure of the excision reporter plasmid PTCR9. Fragments of pTCR9 corresponding to PAT112 and plL205 are represented by black and open areas, respectively. The $6 \mathrm{bp}$ overlap sequences (atttta, ataata) at the integration site of PAT112 in the cat gene of plL205 to produce pTCR9 are indicated. Resolution of pTCR9 into its two components occurs by excision of pAT112 provided that the bacterial host synthesizes the appropriate amount of excisionase and integrase. The two alternative hexanucleotides in PAT112 and pIL205 after excision are shown. aphA3, 3'-aminoglycoside phosphotransferase gene; att- $T n_{1}$ and att- $T n_{R}$, left and right attachment sites, respectively; cat, chloramphenicol acetyltransferase gene; $\Delta$ cat and cat $\Delta, 5^{\prime}$ - and $3^{\prime}$-truncated cat gene; erm, erythromycin-resistance methyltransferase gene; Int-Tn, transposon-encoded integrase; mob, mobilization functions; oriR, replication origin; tra, transfer functions; Xis$\mathrm{Tn}$, transposon-encoded excisionase. The plasmids are not drawn to scale.

Thus, provided that a co-resident transposon synthesizes the appropriate intracellular amount of Xis-Tn and IntTn, pTCR9 can be resolved into its two basic components, the $\mathrm{Cm}^{\mathrm{R}}$ plasmid pIL205 and the $\mathrm{Em}^{\mathrm{R}}$ plasmid pAT112 which does not replicate in a Gram-positive host (Fig. 1). Plasmid pTCR9 was introduced by conjugation into E. faecalis strains BM4110, NEM429, NEM574 and NEM575, L. monocytogenes strains L028Str and NEM766, S. gordonii strains BM120 and NEM768, S. pneumoniae strains BM124 and NEM751, and L. lactis strains MG1363-RF and NEM536. For each of these strains, aliquots of early stationary phase cultures were spread onto BHI agar containing chloramphenicol. Excision of pAT112 from pTCR9 to produce $\mathrm{Cm}^{\mathrm{R}}$ clones was detected in strains of $E$. faecalis, L. monocytogenes and S. gordonii and always depended upon the presence of Tn916 in the bacterial host (Table 2). The frequency of excision of pAT112 ranged from $5.5 \times 10^{-6}$ to $4.5 \times 10^{-8}$, depending upon the (a)

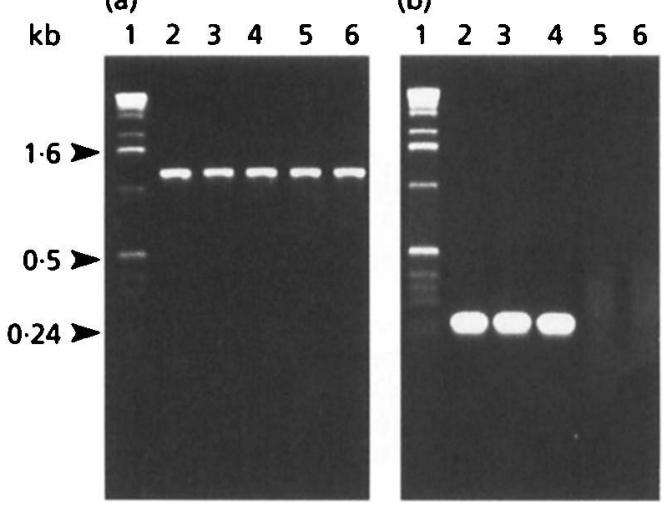

Fig. 2. Agarose gel electrophoresis of PCR products obtained by using primers enabling amplification of int-Tn (a) and of att-Tn (b). The substrates were as follows. Lanes: 1, $1 \mathrm{~kb}$ ladder (Gibco $\mathrm{BRL}) ; 2$, E. faecalis NEM429; 3, L. monocytogenes NEM766; 4, S. gordonii NEM768; 5, S. pneumoniae NEM751; 6, L. lactis NEM536.

strains considered. $\mathrm{Cm}^{\mathbf{R}}$ clones were never obtained in S. pneumoniae NEM751 and L. lactis NEM536 carrying Tn916, which suggests that, in these bacteria, the transposon is unable to promote the excision of pAT112 as well as its own excision. This hypothesis was further substantiated by using a PCR assay which allowed amplification of a $240 \mathrm{bp}$ fragment corresponding to the attachment site of the circularized transposon. As expected, this specific DNA fragment was detected within the DNA templates of E. faecalis NEM429, $L$. monocytogenes NEM766 and $S$. gordonii NEM768, but not in those of L. lactis NEM536 and S. pneumoniae NEM751 (Fig. 2), or in that of S. pneumoniae BM4200, which harbours the closely related conjugative transposon $\operatorname{Tn} 1545$ (data not shown). In these experiments, the amplification of a $1215 \mathrm{bp}$ DNA fragment corresponding to int-Tn served as a positive control (Fig. 2). This analysis confirmed that $\operatorname{Tn} 916$ is unable to excise in L. lactis NEM536 and in S. pneumoniae NEM751 and BM4200.

\section{Phenotypic and genotypic analysis of pAT112 excisants}

The resistance phenotype of a minimum of $20 \mathrm{Cm}^{\mathrm{R}}$ colonies of E. faecalis, L. monocytogenes and S. gordonii obtained on a single plate inoculated with the penultimate proficient dilution was studied by the agar disk diffusion technique (Table 2). The mean values obtained from two experiments revealed that, depending upon the strain considered, $5-36 \%$ of the selected excisants were also $\mathrm{Em}^{\mathrm{R}}$. As opposed to the $\mathrm{Cm}^{\mathrm{R}}$ determinant, the gene conferring resistance to erythromycin in these strains was not transferable by conjugation (data not shown). These results indicated that the non-replicative plasmid pAT112, following excision from pTCR9, had inserted into the chromosome of the host. The presence of pAT112 sequences in the chromosome of $\mathrm{Em}^{\mathrm{R}}$ excisants was consistently revealed by Southern blot 


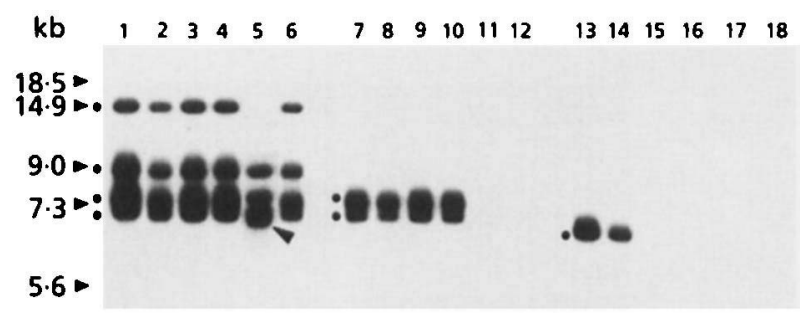

Fig. 3. Southern blot analysis of $\mathrm{Cm}^{\mathrm{R}}$ excisants of strains of $E$. faecalis harbouring plasmid pTCR9. Bacterial DNA was purified, digested with Hindlll, resolved by agarose gel $(0.8 \%, w / v)$ electrophoresis, transferred onto a nitrocellulose membrane, and hybridized with ${ }^{32} \mathrm{P}$-labelled int-Tn to detect sequences related to Tn916 and to characterize the transposon-chromosome junction fragment(s) carrying int-Tn. Lanes: 1, E. faecalis NEM429; 2, NEM429(pTCR9); 3-5, $\mathrm{Tc}^{\mathrm{R}} \mathrm{Em}^{\mathrm{S}}$ NEM429(pTCR9) excisants; 6, $\mathrm{Tc}^{\mathrm{R}} \mathrm{Em}^{\mathrm{R}}$ NEM429(pTCR9) excisant; 7, E. faecalis NEM575; 8, NEM575(pTCR9); 9 and 10, Tc $^{\mathrm{R}} \mathrm{Em}^{\mathrm{S}}$ NEM575(pTCR9) excisants; 11, $\mathrm{Tc}^{S} \mathrm{Em}^{\mathrm{R}}$ NEM575(pTCR9) excisant; 12, $\mathrm{TC}^{\mathrm{S}} \mathrm{Em}^{\mathrm{S}}$ NEM575(pTCR9) excisant; 13, $E$. faecalis NEM574; 14, NEM574(pTCR9); 15 and 16, Tc $^{5}$ Em $^{R}$ NEM574(pTCR9) excisants; 17 and 18, $\mathrm{TC}^{5} \mathrm{Em}^{5}$ NEM574(pTCR9) excisants. Black dots show transposon-chromosome junction fragments containing int-Tn in the parental strains.

hybridization (data not shown). It is noteworthy that almost all $\mathrm{Cm}^{\mathrm{R}}$ excisants originating from $E$. faecalis NEM574, L. monocytogenes NEM766 and S. gordonii NEM768 were susceptible to tetracycline. By contrast, the majority of pAT112 excisants in E. faecalis NEM429 and $25-40 \%$ of those originating in E. faecalis NEM 575 were tetracycline-resistant $\left(\mathrm{Tc}^{\mathrm{R}}\right)$. Southern analysis revealed that none of the genomic DNA extracted from E. faecalis, L. monocytogenes and $S$. gordonii excisants susceptible to tetracycline hybridized with a DNA probe specific to the transposon-encoded integrase gene int-Tn (Fig. 3, lanes 11, 12 and 15-18, shows part of this analysis). The intracellular mobility of $\mathrm{Tn} 916$ in $\mathrm{Tc}^{\mathrm{R}}$ excisants derived from strains containing multiple copies of the transposon was studied as follows. The genomic DNA of $18 \mathrm{Tc}^{\mathbf{R}}$ excisants of E. faecalis NEM429 and corresponding to all $\mathrm{Cm}^{\mathrm{R}}$ clones obtained on a single plate were purified and analysed by Southern blot hybridization using the int-Tn-specific DNA probe. All but one clone possessed a hybridization pattern indistinguishable from that of the parental strain (Fig. 3, lanes 3,4 and 6, shows part of this analysis) and the movement of one copy of Tn916 from one chromosomal locus to another was observed in the remaining clone (Fig. 3, lane 5). A similar study revealed that all $\mathrm{Cm}^{\mathrm{R}}$ excisants of $E$. faecalis NEM575 resistant to tetracycline possessed a hybridization pattern indistinguishable from that of the parental strain (Fig. 3, lanes 9 and 10, shows part of this analysis).

\section{Excision of pAT112 during bacterial growth and under various stress conditions}

The excision of pAT112 was studied during the growth of E. faecalis NEM429 and L. monocytogenes NEM766. The ratio of $\mathrm{Cm}^{\mathbf{R}}$ excisants/total c.f.u. increased

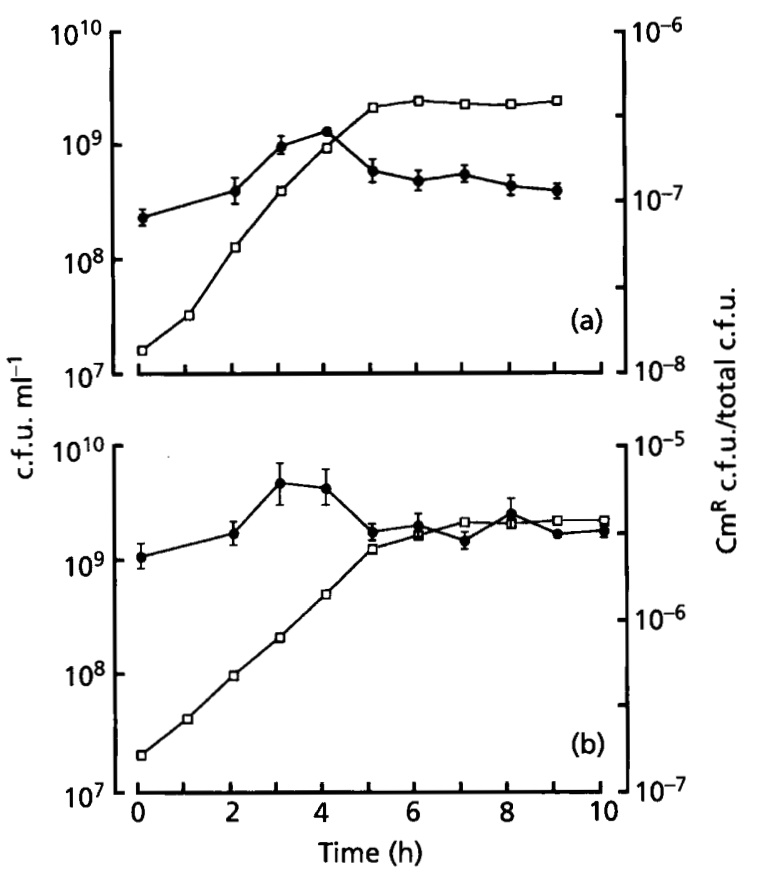

Fig. 4. Excision of PAT112 from pTCR9 during the growth of (a) E. faecalis NEM429 and (b) L. monocytogenes NEM766. Experiments were performed in duplicate and the mean values \pm standard deviations were plotted. $\square$, c.f.u. $\mathrm{ml}^{-1} ; 0$, $\mathrm{Cm}^{\mathrm{R}}$ c.f.u./total c.f.u.

biphasically during the exponential phase of growth of both bacteria and a maximum rate of increase was observed during the late exponential phase (Fig. 4). This ratio slightly decreased as the cells entered the stationary phase and then reached a plateau. These results indicate that excision of pAT112 occurred only during the exponential growth phase of $E$. faecalis and $L$. monocytogenes and mainly during their late exponential phase of growth.

To investigate if excision of pAT112 might be triggered by environmental stresses, cells of E. faecalis NEM429 in the late exponential growth phase were submitted for a short period to commonly used stress inducers (salt, ethanol, heat) at doses that severely reduced cell growth and $\mathrm{Cm}^{\mathrm{R}}$ excisants were enumerated immediately after the treatment. None of these stresses was found to increase the frequency of excision of pAT112 in NEM429 (data not shown). Similarly, neither the addition of tetracycline during this phase of growth nor the presence of this antibiotic throughout the cultivation of NEM429 modified the excision frequency of pAT112 (data not shown).

\section{DISCUSSION}

This paper describes the use of the excision reporter plasmid pTCR9 to carry out a detailed analysis of the intracellular mobility of the conjugative transposon Tn916 in various Gram-positive bacteria. Resolution of this plasmid into its two replicon components to give 
$\mathrm{Cm}^{\mathrm{R}}$ clones might occur by trans-complementation in strains synthesizing the appropriate amount of excisionase and integrase (Fig. 1). To test the functionality of this approach, plasmid pTCR9 was introduced into E. faecalis BM4110, L. monocytogenes L028Str, S. gordonii BM120, L. lactis MG1363-RF and S. pneumoniae BM124 harbouring or not harbouring $\operatorname{Tn} 916 . \mathrm{Cm}^{\mathrm{R}}$ excisants were only obtained in strains of E. faecalis, L. monocytogenes and $S$. gordonii containing Tn916 (Table 2) and, as expected, a PCR analysis revealed that the accomplishment of the recombination event responsible for the expression of this resistance phenotype always depends upon the ability of the bacterial host to generate circularized forms of the transposon (Fig. 2). These results demonstrate the reliability of the excision reporter system developed in this study. Excision of Tn916 and Tn916-mediated excision of pAT112 were not detected in S. pneumoniae BM120 whereas the att-Tn site of circular intermediates of the Tn916-like transposon Tn5251 has been amplified by PCR in S. pneumoniae strain DP1322 (Provvedi et al., 1996). The ability of Tn916-like elements to excise could therefore differ between strains belonging to the same species. Bacterial strains in which Tn916 and pAT112 do not excise are unable to act as transposon donors in mating experiments (Table 2; Fig. 2). These results are consistent with the demonstration that excision is the initial step of both the intracellular and intercellular mobility of this class of elements (Storrs et al., 1991). It should be mentioned, however, that the Tn916-related element Tn1545, which does not excise in S. pneumoniae BM4200, can be conjugatively transferred from this strain to $E$. faecalis recipients (Buu-Hoï \& Horodniceanu, 1980; Courvalin \& Carlier, 1987). Structural analysis of Tn1545 in S. pneumoniae BM4200 has revealed that this transposon constitutes the central part of a large conjugative element that possesses its own transposition and transfer functions (Le Bouguénec et al., 1990). Conjugal transfer of Tn1545 from $S$. pneumoniae $\mathrm{BM} 4200$ to E. faecalis recipients might therefore simply result from its passive transfer in association with the external element. The fact that conjugal transfer of the Tn916-like element Tn5251, which constitutes the central part of the composite element Tn5253, could not be detected independently from that of the bearing conjugative element Tn5252 in matings between $S$. pneumoniae strains constitutes further support for this hypothesis (Provvedi et al., 1996). Excision of Tn916 and Tn916-mediated excision of pAT112 were detected in S. gordonii BM120, whereas this strain did not transfer Tn916 at a detectable frequency. These results suggest that the transfer functions of $\operatorname{Tn} 916$ are not conveniently expressed in this strain and demonstrate that excision is not sufficient for conjugal transfer to occur. That Tn916 cannot undergo conjugative transposition from $S$. gordonii BM120 to E. faecalis JH2-2 opposes the previous report of conjugal transfer of the Tn916-related transposon Tn 3703 between the same bacterial strains (S. gordonii BM124 was formerly designated $S$. sanguis Challis BM124) (Le Bouguénec et al., 1984). These conflicting results possibly reflect the fact that $\operatorname{Tn} 3703$ is part of a large conjugative element designated Tn3701 (Le Bouguénec et al., 1990). Thus, the acquisition of a broader host range of transfer by Tn916-like elements such as Tn1545 or Tn 3703 might constitute the selective pressure responsible for the genesis of the large composite conjugative transposons that are widespread in streptococci (Clermont \& Horaud, 1994; David et al., 1993; Le Bouguénec et al., 1990).

It is noteworthy that, whatever the bacterial species considered, all $\mathrm{Cm}^{\mathrm{R}}$ excisants derived from strains containing a single copy of $\operatorname{Tn} 916$ were cured of their element (Table 2; Fig. 3, lanes 11, 12 and 15-18, shows part of this analysis). This phenomenon is less pronounced in the case of E. faecalis NEM575, which carries two copies of $\operatorname{Tn} 916$, since only $60-75 \%$ of its $\mathrm{Cm}^{\mathrm{R}}$ excisants have lost the two elements present in the parental strain. By contrast, only $5-10 \%$ of the $\mathrm{Cm}^{\mathrm{R}}$ excisants derived from E. faecalis NEM429 have lost the four copies of Tn916 (Table 2). Southern blot analysis of $\mathrm{Cm}^{\mathrm{R}} \mathrm{Tc}^{\mathrm{R}}$ excisants revealed that all clones derived from NEM575 (Fig. 3, lanes 9 and 10) and that all but one clone derived from NEM429 (Fig. 4) have retained all copies of $\operatorname{Tn} 916$ at the same locations as in the parental strains. Taken together, these results suggest that (i) an excision event in a strain carrying multiple $\operatorname{Tn} 916$ insertions may produce two major classes of excisants, those in which all copies of the element excised (typified by the excisants cured of $\operatorname{Tn} 916$ ) and those in which a single copy excised, and (ii) an inverse correlation between the copy number of chromosome-borne transposons and the relative proportions of these two classes of excisants may exist. It has been proposed that when there is more than one copy of Tn916 in the cell, the movement of one element activates the movement of all others (Clewell et al., 1995; Flannagan \& Clewell, 1991). Our data are not fully consistent with this hypothesis since the mobility of all copies of $\operatorname{Tn} 916$ was found to accompany that of pAT112 in $67 \%$ and only $7.5 \%$ of the $\mathrm{Cm}^{\mathrm{R}}$ excisants derived from NEM 575 and NEM429, respectively. Moreover, the detection of the movement of a single copy of $\mathrm{Tn} 916$ in a $\mathrm{Cm}^{\mathrm{R}}$ excisant derived from E. faecalis NEM429 (Fig. 3, lane 5) demonstrated the ability of a copy of Tn916 to excise alone in a high donor potential strain carrying multiple Tn916 insertions.

Determination of the dosage of Tn916 circular intermediates in various $E$. faecalis strains by using a quantitative PCR assay has led to the conclusion that Tn916 conjugation frequency is directly proportional to the copy number of circular intermediates present in the donor cell population (Manganelli et al., 1995). However, data obtained by using non-quantitative PCR assays have led to a similar (Jaworski \& Clewell, 1994) or to the opposite (Rice et al., 1992) conclusion. The excision frequency of pAT112, defined as the number of $\mathrm{Cm}^{\mathrm{R}}$ excisants/total c.f.u., reflects the number of cells within a given bacterial population in which the amount of Xis-Tn and Int-Tn enabled an excision event to occur. The excision frequency of pAT112 obtained with 
the three isogenic strains E. faecalis NEM429, NEM574 and NEM575 is within the same order of magnitude whereas their transposon donor potential varies by more than two orders of magnitude (Table 2). Phenotypic (Table 2) and genotypic (Fig. 3, lanes 3-6, shows part of this analysis) characterization of $\mathrm{Cm}^{\mathrm{R}}$ excisants of E. faecalis NEM429 harbouring pTCR9 revealed that the four copies of Tn916 plus pAT112 had excised in $7.5 \%$ of the clones studied, and one copy of Tn 916 plus pAT112 had excised in $5 \%$ of the clones studied, whereas only pAT112 had excised in $87.5 \%$ of the clones studied. These data suggest that, once an excision event had occurred in NEM429, 87.5\%, $5 \%$ and $7 \cdot 5 \%$ of the excisants produced one copy, two copies and four copies of Tn916 circular intermediates, respectively. A similar analysis led us to conclude that, in the case of NEM $575,32.5 \%$ and $67.5 \%$ of the excisants produced one copy and two copies of Tn916 circular intermediates, respectively. One can therefore assume that, on average, every excisant of NEM429, NEM575 and NEM574 produces 1.28 copies $(7.5 \% \times$ four copies + $5 \% \times$ two copies $+87.5 \% \times$ one copy), 1.67 copies $(67.5 \% \times$ two copies $+32.5 \% \times$ one copy) and one copy of Tn916 circular intermediates, respectively. The copy number of $\operatorname{Tn} 916$ circular intermediates per cell can then be estimated for NEM429, NEM575 and NEM574 as the mean number of Tn916 circular intermediates produced by the corresponding excisants multiplied by the frequency of pAT112 excision in these strains. These values were $3.4 \times 10^{-7}, 7.9 \times 10^{-8}$ and $8.35 \times 10^{-8}$ for NEM429, NEM575 and NEM574, respectively. Thus, there is apparently no linear relationship between the donor potential of E. faecalis NEM429, NEM574 and NEM575 and either the excision frequency of pAT112 or the copy number of $\operatorname{Tn} 916$ circular intermediates per cell in these strains. Taken together, these results indicate that, although excision might contribute to defining the donor potential of the host, other factors are likely to be involved in the conjugation process. It has been proposed that the differences in Tn916 transfer potential are related to differences in excision frequencies influenced by the nucleotide sequence of the 6 bp junction fragments (Jaworski \& Clewell, 1994). An alternative possibility could be that the sequence of the $6 \mathrm{bp}$ junction fragments influences the binding and/or activity of proteins that modulate the expression of the transfer functions. Analysis of excision of pAT112 during the growth of E. faecalis NEM429 and $L$. monocytogenes NEM766 revealed an increase in the rate of excision during the late exponential phase (Fig. 4). A similar observation was made when the copy number of Tn916 circular intermediates was quantified by PCR (Manganelli et al., 1995). These results suggested that the excision of Tn916 may be regulated by some host factors, as previously suggested by Bringel et al. (1991). It is conceivable that these factors are missing in bacterial hosts such as L. lactis MG1363 and S. pneumoniae BM124 and BM4200 where $\operatorname{Tn} 916$ is unable to excise. Finally, the role of environmental stresses in the excision of $\operatorname{Tn} 916$ was studied and our results indicate that this recombination event is ap- parently not stimulated by heat shock, salt and alcohol stresses.

We demonstrated that the presence of tetracycline in the mating medium increased the transfer frequency of Tn1545 (Doucet-Populaire et al., 1991). This observation was confirmed for several Tn916-like elements (Rice et al., 1995; Torres et al., 1991), including the prototype element Tn916 (Showsh \& Andrew, 1992), and it has been proposed that tetracycline-stimulated excision of the element would result in an increase in excision frequency and, in turn, in an increase in conjugation frequency (Manganelli et al., 1995). The molecular basis for this hypothesis would be that the tetracycline-inducible tet $M$ transcript might activate the transcription of the downstream genes xis-Tn and intTn (Rice et al., 1992). We do not agree with the hypothesis that tetracycline induces the excision of Tn916-like elements for the following reasons: (i) increased transcription of xis-Tn and int-Tn is not supposed to result in an increase of excision since this would not modify the ratio of the corresponding proteins; (ii) excision of $\mathrm{Tn} 916$ from the insertionally inactivated haemolytic gene carried by the IncHly plasmid pIP964, as measured by the reversion towards the haemolytic phenotype, did not increase when an $E$. faecalis host was cultivated in the presence of tetracycline (data not shown); (iii) the frequency of excision of pAT112 from pTCR9 was not increased when $E$. faecalis NEM429 was cultivated in the presence of tetracycline. We propose rather that, following excision, a tetracycline-inducible transcript reads through the newly formed transposon attachment site to activate the tra determinants carried by the other arm of the transposon. Further work is required to substantiate this hypothesis.

\section{ACKNOWLEDGEMENTS}

We thank S. Naïr for critical reading of the manuscript and P. Berche for his interest in this work and material support. This work was supported by the Institut National de la Santé et de la Recherche Médicale and the University of Paris V.

\section{REFERENCES}

Bringel, F., Van Alstine, G. L. \& Scott, J. R. (1991). A host factor absent from Lactococcus lactis subspecies lactis MG1363 is required for conjugative transposition. Mol Microbiol 5, 2983-2993.

Buu-Hoì, A. Y. \& Horodniceanu, T. (1980). Conjugative transfer of multiple antibiotic resistance markers in Streptococcus pneumoniae. J Bacteriol 143, 313-320.

Churchward, G., Belin, D. \& Nagamine, Y. (1984). A pSC101derived plasmid which shows no sequence homology to other commonly used cloning vectors. Gene 31, 165-171.

Clermont, D. \& Horaud, T. (1994). Genetic and molecular studies of a composite chromosomal element ( $\operatorname{Tn} 3705)$ containing a Tn916-modified structure ( $\operatorname{Tn} 3704)$ in Streptococcus anginosus F22. Plasmid 31, 40-48.

Clewell, D. B., Flannagan, S. E. \& Jaworski, D. D. (1995). Unconstrained bacterial promiscuity: the Tn916-Tn1545 family of conjugative transposons. Trends Microbiol 3, 229-236. 
Courvalin, P. \& Carlier, C. (1986). Transposable multiple antibiotic resistance in Streptococcus pneumoniae. Mol Gen Genet 205, 291-297.

Courvalin, P. \& Carlier, C. (1987). Tn1545: a conjugative shuttle transposon. Mol Gen Genet 206, 259-264.

David, F., de Cespédès, G., Delbos, F. \& Horaud, T. (1993). Diversity of chromosomal genetic elements and gene identification in antibiotic-resistant strains of Streptococcus pneumoniae and Streptococcus bovis. Plasmid 29, 147-153.

Doucet-Populaire, F., Trieu-Cuot, P., Dosbaa, I., Andremont, A. \& Courvalin, P. (1991). Inducible transfer of conjugative transposon Tn1545 from Enterococcus faecalis to Listeria monocytogenes in the digestive tract of gnotobiotic mice. Antimicrob Agents Chemother 35, 185-187.

Flannagan, S. \& Clewell, D. B. (1991). Conjugative transfer of Tn916 in Enterococcus faecalis: trans activation of homologous transposons. J Bacteriol 173, 7136-7141.

Flannagan, S. E., Zitzow, L. A., Su, Y. A. \& Clewell, D. B. (1994). Nucleotide sequence of the $18-\mathrm{kb}$ conjugative transposon $\mathrm{Tn} 916$ from Enterococcus faecalis. Plasmid 32, 350-354.

Jacobs, A. E. \& Hobbs, S. J. (1974). Conjugal transfer of plasmidborne multiple antibiotic resistance in Streptococcus faecalis var. zymogenes. J Bacteriol 117, 360-372.

Jaworski, D. D. \& Clewell, D. B. (1994). Evidence that the coupling sequences play a frequency-determining role in conjugative transposition of $\operatorname{Tn} 916$ in Enterococcus faecalis. J Bacteriol 176, 3328-3335.

Jaworski, D. D. \& Clewell, D. B. (1995). A functional origin of transfer (oriT) on the conjugative transposon Tn916. J Bacteriol 177, 6644-6651.

Langella, P., Le Loir, Y., Ehrlich, S. D. \& Gruss, A. (1993). Efficient plasmid mobilization by pIP501 in Lactococcus lactis subsp. lactis. J Bacteriol 175, 5806-5813.

Le Bouguénec, C., Horaud, T., Bieth, G., Colimon, R. \& Dauguet, C. (1984). Translocation of antibiotic resistance markers of a plasmid-free Streptococcus pyogenes (group A) strain into different streptococcal hemolysin plasmids. Mol Gen Genet 194, 377-387.

Le Bouguénec, C., de Cespédès, G. \& Horaud, T. (1990). Presence of chromosomal elements resembling the composite structure Tn3701 in streptococci. J Bacteriol 172, 727-734.

Manganelli, R., Romano, L., Ricci, S., Zazzi, M. \& Pozzi, G. (1995). Dosage of Tn916 circular intermediates in Enterococcus faecalis. Plasmid 34, 48-57.

Poyart, C. \& Trieu-Cuot, P. (1994). Heterogeneric conjugal transfer of the pheromone-responsive plasmid pIP964 (IncHlyI) of Enterococcus faecalis in the apparent absence of pheromone induction. FEMS Microbiol Lett 122, 173-180.

Poyart, C., Celli, J. \& Trieu-Cuot, P. (1995). Conjugative transposition of Tn916-related elements from Enterococcus faecalis to Escherichia coli and Pseudomonas fluorescens. Antimicrob Agents Chemother 39, 500-506.

Poyart-Salmeron, C., Trieu-Cuot, P., Carlier, C. \& Courvalin, P.
(1989). Molecular characterization of two proteins involved in the excision of the conjugative transposon $\mathrm{Tn} 1545$ : homologies with other site-specific recombinases. EMBO J 8, 2425-2433.

Poyart-Salmeron, C., Trieu-Cuot, P., Carlier, C. \& Courvalin, P. (1990). The integration-excision system of the streptococcal transposon $\operatorname{Tn} 1545$ is structurally and functionally related to those of lambdoïd phages. Mol Microbiol 4, 1513-1521.

Provvedi, R., Manganelli, R. \& Pozzi, G. (1996). Characterization of conjugative transposon $\operatorname{Tn} 5251$ of Streptococcus pneumoniae. FEMS Microbiol Lett 135, 231-236.

Rice, L. B., Marshall, S. H. \& Carias, L. L. (1992). Tn5381, a conjugative transposon identifiable as a circular form in Enterococcus faecalis. J Bacteriol 174, 7308-7315.

Rice, L. B., Carias, L. L. \& Marshall, S. H. (1995). Tn5384, a composite enterococcal mobile element conferring resistance to erythromycin and gentamicin whose ends are directly repeated copies of IS256. Antimicrob Agents Chemother 39, 1147-1153.

Sambrook, J., Fritsch, E. F. \& Maniatis, T. (1989). Molecular Cloning: a Laboratory Manual, 2nd edn. Cold Spring Harbor, NY: Cold Spring Harbor Laboratory.

Scott, J. R. \& Churchward, G. G. (1995). Conjugative transposition. Annu Rev Microbiol 49, 367-397.

Showsh, S. A. \& Andrew, R. E. J. (1992). Tetracycline enhances Tn916-mediated conjugal transfer. Plasmid 28, 213-224.

Simon, R., Priefer, U. \& Puhler, A. (1983). A broad host range mobilization system for in vivo genetic engineering: transposon mutagenesis in Gram-negative bacteria. Biotechnology 1, 784-794.

Storrs, M. J., Poyart-Salmeron, C., Trieu-Cuot, P. \& Courvalin, P. (1991). Conjugative transposition of $\operatorname{Tn} 916$ requires the excisive and integrative activities of the transposon-encoded integrase IntTn. J Bacteriol 173, 4347-4352.

Torres, O. R., Korman, R. Z., Zahler, S. A. \& Dunny, G. M. (1991). The conjugative transposon Tn925: enhancement of conjugal transfer by tetracycline in Enterococcus faecalis and mobilization of chromosomal genes in Bacillus subtilis and E. faecalis. Mol Gen Genet 225, 395-400.

Trieu-Cuot, P., Carlier, C. \& Courvalin, P. (1988). Conjugative plasmid transfer from Enterococcus faecalis to Escherichia coli. J Bacteriol 170, 4388-4391.

Trieu-Cuot, P., Carlier, C., Poyart-Salmeron, C. \& Courvalin, P. (1991). An integrative vector exploiting the transposition properties of Tn1545 for insertional mutagenesis and cloning of genes from Gram-positive bacteria. Gene 106, 21-27.

Trieu-Cuot, P., de Cespédès, G. \& Horaud, T. (1992). Nucleotide sequence of the chloramphenicol resistance determinant of the streptococcal plasmid pIP501. Plasmid 28, 272-276.

Zhang, H., Scholl, R., Browse, J. \& Somerville, C. (1988). Doublestranded DNA sequencing as a choice for DNA sequencing. Nucleic Acids Res 16, 120.

Received 21 August 1996; revised 27 November 1996; accepted 29 November 1996. 